\title{
Comparative Study of Some Alternatives for the Reuse of Calcareous Mud in Egypt
}

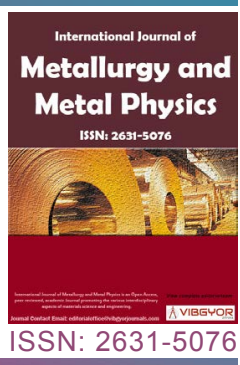

\section{Elsayed MA Rassoul1,2 and Roshdy Abdel Rassoul ${ }^{*}$}

${ }^{1}$ Faculty of Engineering, Mansoura University, Egypt

${ }^{2}$ Member, American Institute of Mining, Metallurgical, and Petroleum Engineers (AIME), USA

${ }^{3}$ Arab Academy for Science \& Technology, Alexandria, Egypt

\begin{abstract}
The chemical analysis of the calcareous mud (CM) which is produced as a by-product from the Egyptian sugar beet companies was the corner stone behind the idea of this research. From the chemical analysis, it was found that the $\mathrm{CM}$ consists mainly of $\mathrm{CaCO}_{3}, \mathrm{MgCO}_{3}$, and about from 10 to $15 \%$ organic matter. The organic matter present in the $\mathrm{CM}$ is considered by all means as an added value, especially when the $\mathrm{CM}$ is going to be used in pyro-industrial applications. In this paper, three different alternatives will be investigated in order to choose the best of them.

The first alternative was replacing the limestone (LS) used in the sintering of El-Bahareya iron ores in the Egyptian Iron and Steel Company (Hadisolb) by the CM. In this respect, several pilot scale experiments were performed in Hadisolb. The performed experiments covered replacements of LS by the CM from zero to $100 \%$, with an increment of $10 \%$ each time. Chemical analyses and drum tests were performed for each run of experiments. Taking into considerations both the productivity and the sinter quality, the results proved that at least $10 \%$ reduction in coke consumption can be achieved, due to the replacement of LS in the sintering process by the CM.

The second alternative is using the $\mathrm{CM}$ in the Charge Mix of the Calcination Furnace in cement companies. The performed experiments in Alexandria Portland Cement Company (APCC) proved that although the use of the CM in the mix is technically useful, but is not economic.

Aside from these two alternatives (pyro-industrial applications), a third alternative based on the advantage of offering CM for free, is used as a back-filling material (BFM) for the underground cables carrying the electric current. It is well known that the current carrying capacities of the cables are highly affected by the thermal resistivity of the BFM. The results of using the CM as a BFM for the underground cables compared with sand which is used nowadays by the current transmission companies in Egypt indicated that the current carrying capacity for cables of the same material and diameter was highly increased by using the $\mathrm{CM}$ as a BFM instead of sand.
\end{abstract}

\section{Keywords}

Calcareous mud, Sintering, Calcination furnace, Back-filling material, Thermal resistivity, Current carrying capacity

\footnotetext{
*Corresponding author: Roshdy Abdel Rassoul, Arab Academy for Science \& Technology, Alexandria, Egypt

Accepted: March 24, 2020; Published: March 26, 2020

Copyright: (c) 2020 Rassoul EMA, et al. This is an open-access article distributed under the terms of the Creative Commons Attribution License, which permits unrestricted use, distribution, and reproduction in any medium, provided the original author and source are credited.
}

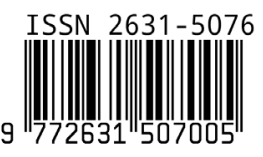

Rassoul and Rassoul. Int J Metall Met Phys 2020, 5:049 


\section{Introduction}

There are eight sugar beet companies in Egypt now. Beside sugar they produce several by-products, including the calcareous mud (CM), which is the only unused product, considered as a waste material, and is accumulated year after year causing a lot of environmental and economic problems. As a matter of fact, the amount of the CM is about 8-12 w/o of the processed beet, which means that the total annual production of the $\mathrm{CM}$ is estimated to be about 800,000 tons. It may be worthy to mention here that in Europe the CM is reused in several aspects, such as an additive to animal feed, as a filling material in some industrial products (e.g. rubber, plastic, paper, in the building industry, and in water treatment). However, in Egypt the CM is still unused, in spite of the fact that the sugar beet companies offer to give it free of charge.

Far from the pyro-industrial applications, and taking an advantage of giving the $\mathrm{CM}$ free of charge, it may be worthy to suggest to the electric current transmission companies to use it as a back-filling material (BFM) for the underground cables instead of sand.

\section{Materials and Experiments}

\section{First alternative: Iron ore sintering in (Had- isolb) [1]}

In many cases, sintering is considered as an essential step in ore preparation for the blast furnace operation. Sintering may be defined as the agglomeration of fine particles into a strong porous mass. The process is carried out by heating the sintering charge at a temperature approaching its fusion. The sintering charge usually includes, beside the iron ores, the required amounts of LS as a flux, coke and water to produce sinter of a specific composition and quality $[2,3]$.

The Egyptian Iron \& Steel Company (Hadisolb) is the only company among all the other steel making companies in Egypt which adopts blast furnace/ sintering route. The blast furnaces in Hadisolb use self-fluxed sinter in its burden. Self-fluxed sinter, as was mentioned before, requires an iron ore, a flux- ing material such as LS and/or CM, coke and water.

\section{Material}

Iron ore: Iron ore deposits at El-Gedida is the only iron ore used now in Hadisolb. This ore is located in three different localities. At El-Gedida mines, ores from the three localities are extracted and blended according to predetermined program to meet the previously agreed upon composition, which is $\mathrm{Fe}>51 \%, \mathrm{Cl}<0.6 \%, \mathrm{MnO}<2.4 \%, \mathrm{SiO}_{2}<$ $8 \%, \mathrm{CaO}>0.5 \%$, and $\mathrm{Al}_{2} \mathrm{O}_{3}<2 \%$ [4].

Limestone (LS): The LS used as a flux in the pilot-scale experiments is brought from Bani-Khalid quarries nearby Samalut. The quarry is owned by Hadisolb, and is one of the highest quality in Egypt. The LS was crushed and sieved up to $3 \mathrm{~mm}$.

Calcareous mud (CM): In this investigation, a scientific approach for the reuse of the $\mathrm{CM}$ is adopted. This approach is based on the chemical analysis of the $\mathrm{CM}$. The chemical analysis for a representative sample of CM was performed using XRF - 9800 ARL technique, and is given in Table 1 [5]. The chemical analysis given in Table 1 shows that the $\mathrm{CM}$ is composed mainly of $\mathrm{CaCO}_{3}, \mathrm{MgCO}_{3}$ and a significant amount of organic matter varies between $10-15 \%$ - expressed as organic $\mathrm{CO}_{2}$ and its value depends on the beet juice composition. The L.O.I. is due to evaporation of water and organic matter. We may consider that the 800,000 tons of $\mathrm{CM}$ - assuming only $10 \%$ organic matter - will contain about 80,000 tons of a fuel, accordingly, it was suggested to reuse the $\mathrm{CM}$ in the sinter plant of the iron and steel company and/or cement companies as a substitute for the LS used in any of them.

The idea of replacing LS by CM in the sintering process is based on the chemical composition of both materials. The chemical analysis for representative samples from Bani-Khaled quarries LS used as a flux material in the sintering plant of Hadisolb and that of CM from Dakahleya Sugar Beet Companies is given in Table 2.

Experiments: Hadisolb is the only company in Egypt, which has sintering plant. In this plant the iron bearing material goes through its final step of

Table 1: Chemical analysis for a representative sample of CM.

\begin{tabular}{|l|l|l|l|l|l|l|l|l|l|l|l|}
\hline \%CaCO $_{3}$ & \% $^{2} \mathrm{MCO}_{3}$ & \multicolumn{3}{l|}{ Elements\% } & & Organic $\mathrm{CO}_{2} \%$ \\
\hline$\% \mathrm{CaO}$ & $\% \mathrm{CO}_{2}$ & $\% \mathrm{MgO}$ & $\% \mathrm{CO}_{2}$ & $\% \mathrm{Al}_{2} \mathrm{O}_{3}$ & $\% \mathrm{Fe}_{2} \mathrm{O}_{3}$ & $\% \mathrm{P}_{2} \mathrm{O}_{5}$ & $\% \mathrm{SiO}_{2}$ & $\% \mathrm{SO}_{3}$ & L.O.I. & \\
\hline 36.19 & 28.5 & 5.7 & 8.3 & 0.24 & 0.17 & 1.3 & 4 & 0.56 & 50.09 & $\sim 15$ \\
\hline
\end{tabular}


preparation since the blast furnaces, are fed by the iron bearing material in the form of sinter.

In this investigation, several pilot scale experiments were performed in the sintering pilot plant

Table 2: Chemical analysis for representative samples from Bani-Khaled quarries LS flux used in the sintering plant of Hadisolb compared with CM from Dakahleya Sugar Beet Company.

\begin{tabular}{|l|l|l|}
\hline Compound\% & Limestone (LS) & $\begin{array}{l}\text { Calcareous mud } \\
\text { (CM) }\end{array}$ \\
\hline Moisture & 0.42 & $\sim 2$ \\
\hline $\mathbf{C a O}$ & 54.71 & 36.19 \\
\hline $\mathbf{A l}_{\mathbf{2}} \mathbf{O}_{\mathbf{3}}$ & 0.06 & 0.24 \\
\hline $\mathbf{F e}_{\mathbf{2}} \mathbf{O}_{\mathbf{3}}$ & 0.12 & 0.17 \\
\hline $\mathbf{M g O}$ & 0.5 & 5.7 \\
\hline $\mathbf{S i O}$ & 0.17 & 4.0 \\
\hline $\mathbf{S O}$ & 0.17 & 0.56 \\
\hline $\mathbf{P}$ & 0.008 & 0.01 \\
\hline Organic $\mathbf{C O}_{\mathbf{2}}$ & -- & $\sim 15$ \\
\hline L.O.I. & 43.78 & 50.09 \\
\hline
\end{tabular}

in Hadisolb. The sintering process requires Coke, Limestone and Moisture beside the iron bearing material. Sintering of different mixtures with various $\mathrm{CM}$ content (ranging from 0 to $100 \%$ in steps of $10 \%$ ) is conducted in a pilot scale unit of $20 \mathrm{~kg}$ capacity within the sintering plant of Hadisolb, as shown in Figure 1 [6].

Second alternative: Charge mix of the calcination furnace in Alexandria Portland Cement Company (APCC)

The performed experiments in APCC proved that although the replacement of LS by the $\mathrm{CM}$ in the calcination furnace is technically feasible, it was found that it is not economic since the cement factories in Egypt have their own nearby LS quarries.

We estimate that for the Alexandria plant capacity 1,400,000-ton clinker/year X $3600 \mathrm{MJ} /$ ton, approximately 5,040,000 GJ/year, the expected cost is about $32.4 \mathrm{EGP} / \mathrm{GJ}$, so the total fuel cost is about 16.2 MEGP/year, and the saving is expected to be $0.6 \%$, which means the saving would be around $979.500 \mathrm{EGP} /$ year.

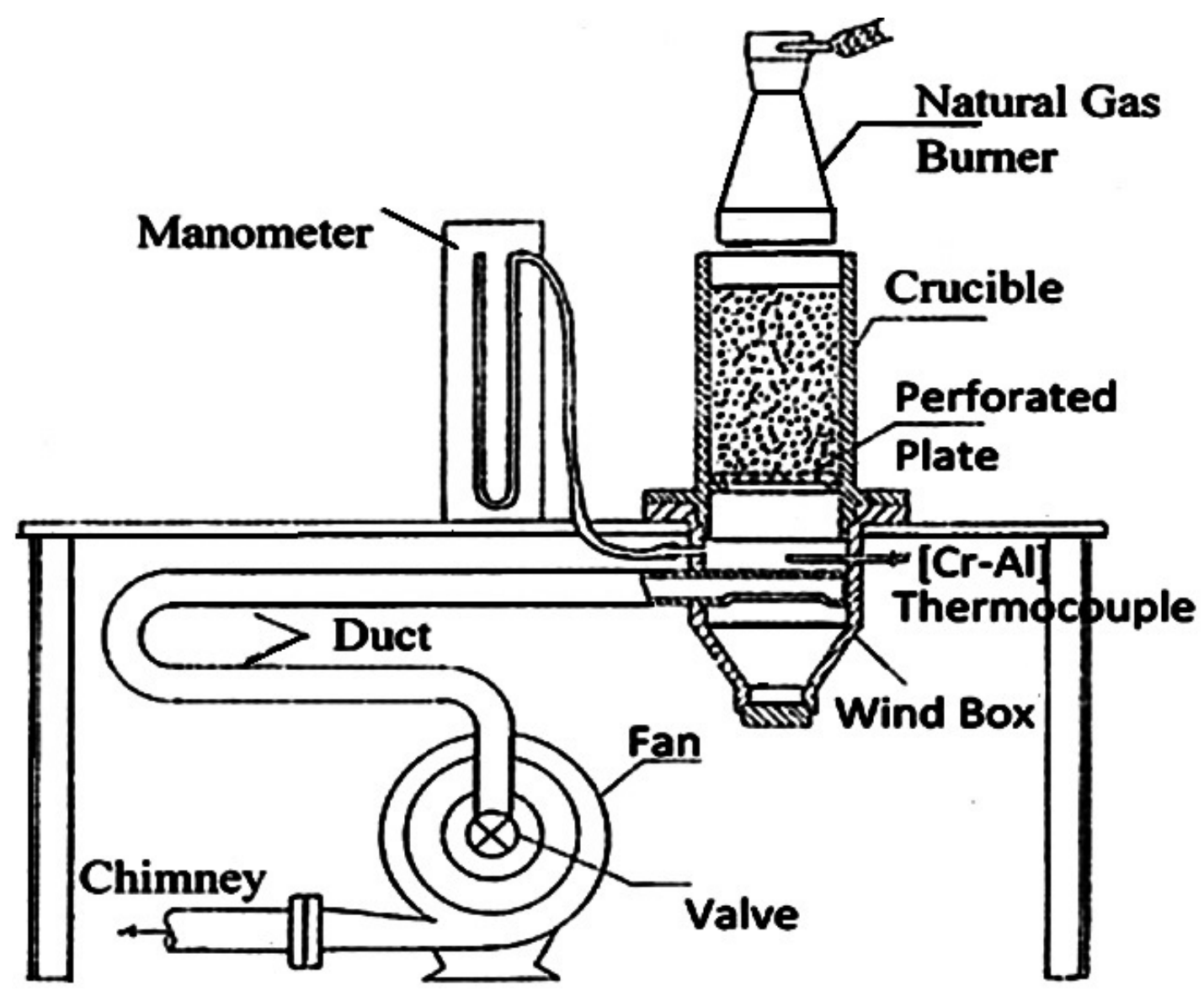

Figure 1: Pilot scale sintering unit. 
Third alternative: The use of $\mathrm{CM}$ as a back-filling material (BFM) for underground cables [7]

Three trials may be undertaken to lower the cost of transmitting electric current by means of underground power cables. The first trial is by selecting cables made from metals of higher electrical conductivity such as copper. The second is by using cables of larger diameters, and the third is by using a BFM of lower thermal resistivity. It is clear that the third one is less expensive compared to the other two, although the third one is less expensive it will lead also to an increase in the current carrying capacities of the cables. As a matter of fact, underground power cables are highly affected by the thermal resistivity of the BFM used as surroundings for the cables. It was found that the current carrying capacity increases as the thermal resistivity of the BFM decreases, and vice-versa. In Europe, sand is commonly used as a BFM for the underground power cables. The thermal resistivity of wet sand is relatively low, it is about $55 \mathrm{k}^{\circ} . \mathrm{cm} / \mathrm{W}$, however it gradually increases as sand becomes dry, it becomes, 75,105 and $396 \mathrm{k}^{\circ} . \mathrm{cm} / \mathrm{W}$ when water content in sand is 20,10 and $\approx 0 \%$. In countries of dry climate such as Egypt and most of the Arab countries, the thermal resistivity of sand is very close to $396 \mathrm{k.cm} / \mathrm{W}$, and thus sand should not be recommended to be used as a BFM for the underground power cables in such countries. In this investigation a trial was made to urge the decision makers in the electric current transmission company in Egypt to use another local material of lower thermal resistivity as a BFM than that of sand [8-10].

Nowadays, sand is the most common materi- al used as a BFM for the cables in Europe and in many other countries including Egypt. As a matter of fact, the thermal resistivity of dry sand -Egypt and Arab world case- is much higher than that for wet sand -Europe case- and thus such sand should not be recommended as a BFM. material for the underground power cables in such countries. $\mathrm{CM}$ however which is abundant in Egypt may be recommended as a BFM material for the underground power cables since its thermal resistivity is much lower than that of sand [7]. It is well known that the current carrying capacities of the underground power cables are strongly affected by the thermal resistivity of the BFM [8]. It was found that a cable of the same material and diameter will carry almost twice as much current when CM is used as a BFM instead of sand [7]. In other words, a cable of half of its diameter and of the same material can carry the same amount of current. So, and according to the electric current transmitting company, the expected savings when using $\mathrm{CM}$ instead of sand as a BFM is estimated to be about two billion EGP/year $[11,12]$.

\section{Results and Discussion}

In order to investigate the effect of replacement of $\mathrm{LS}$ by CM in the sintering process, several sintering experiments were performed, using different percentages of replacements.

Representative samples were taken from each three similar experiments (of the same replacement percent), for chemical analysis. Table 3 and Figure 2 show the average chemical analysis for different sinters ( 3 samples for each composition) as

Table 3: Average chemical analysis for different sinters with different CM\%.

\begin{tabular}{|c|c|c|c|c|c|c|c|}
\hline No & CM\% & Total Fe\% & FeO\% & $\mathrm{Fe}_{2} \mathrm{O}_{3} \%$ & $\mathrm{SiO}_{2} \%$ & $\mathrm{CaO} \%$ & MgO\% \\
\hline 1 & 0 & 52.20 & 13.60 & 59.35 & 8.82 & 9.69 & 1.120 \\
\hline 2 & 10 & 52.15 & 13.6 & 59.2 & 8.80 & 9.55 & 1.200 \\
\hline 3 & 20 & 52.09 & 14.18 & 58.62 & 8.44 & 9.10 & 1.36 \\
\hline 4 & 30 & 52.05 & 14.80 & 57.50 & 8.30 & 8.95 & 1.68 \\
\hline 5 & 40 & 52.05 & 16.68 & 55.57 & 8.06 & 8.88 & 2.20 \\
\hline 6 & 50 & 52.00 & 15.56 & 57.29 & 7.43 & 7.83 & 2.35 \\
\hline 7 & 60 & 52.04 & 13.92 & 58.41 & 7.86 & 7.51 & 2.60 \\
\hline 8 & 70 & 52.00 & 16.87 & 55.35 & 7.78 & 7.4 & 2.80 \\
\hline 9 & 80 & 51.82 & 14.29 & 58.67 & 7.60 & 7.30 & 3.10 \\
\hline 10 & 90 & 51.78 & 15.87 & 55.75 & 7.48 & 7.27 & 3.20 \\
\hline 11 & 100 & 51.57 & 15.12 & 56.88 & 7.20 & 7.20 & 3.30 \\
\hline
\end{tabular}




\section{Chemical analysis for different sinters vs CM \%}

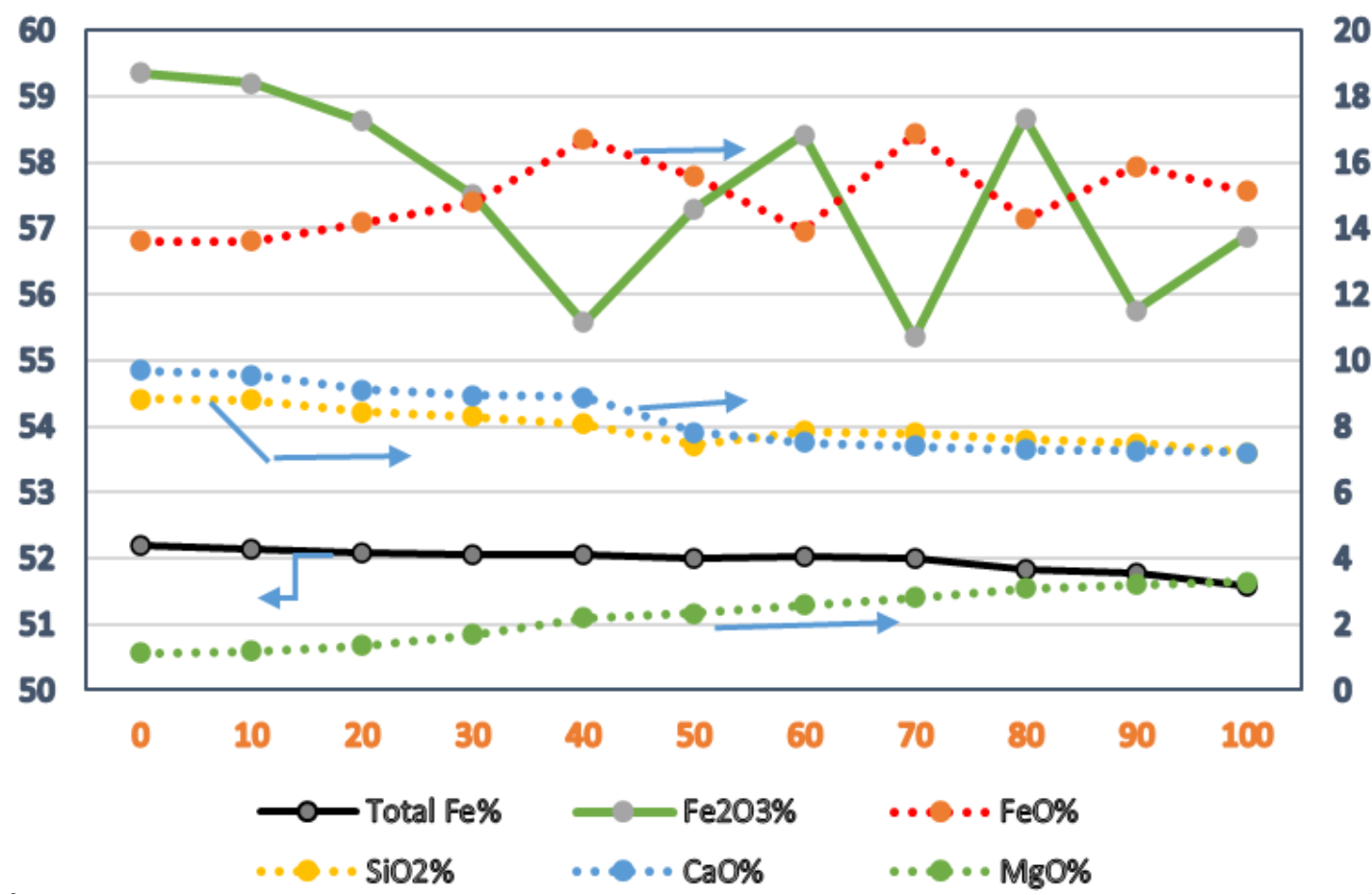

Figure 2: Average chemical analysis for different sinters vs. CM\%.

Table 4: Savings in coke consumption for different sinters with different $\mathrm{CM} \%$.

\begin{tabular}{|l|l|l|l|}
\hline No & CM (\%) & $\begin{array}{l}\text { Saving in coke } \\
\text { (\%) }\end{array}$ & $\begin{array}{l}\text { Drum test } \\
\text { (\%) }\end{array}$ \\
\hline $\mathbf{1}$ & 0 (100\% LS) & 0 & 12.0 \\
\hline $\mathbf{2}$ & $10(90 \% \mathrm{LS})$ & 2 & 12.3 \\
\hline $\mathbf{3}$ & $20(80 \% \mathrm{LS})$ & 4 & 12.5 \\
\hline $\mathbf{4}$ & $30(70 \% \mathrm{LS})$ & 6 & 12.8 \\
\hline $\mathbf{5}$ & $40(60 \% \mathrm{LS})$ & 8 & 13.0 \\
\hline $\mathbf{6}$ & $50(50 \% \mathrm{LS})$ & 9 & 13.2 \\
\hline $\mathbf{7}$ & $60(40 \% \mathrm{LS})$ & 10 & 13.5 \\
\hline $\mathbf{8}$ & $70(30 \% \mathrm{LS})$ & 11 & 13.8 \\
\hline $\mathbf{9}$ & $80(20 \% \mathrm{LS})$ & 12 & 14.0 \\
\hline $\mathbf{1 0}$ & $90(10 \% \mathrm{LS})$ & 14 & 14.2 \\
\hline $\mathbf{1 1}$ & $100(0 \% \mathrm{LS})$ & 15 & 14.5 \\
\hline
\end{tabular}

a function of $\mathrm{CM} \%$ in the sample. From Table 3, it is noticed that the $\mathrm{CaO} \%$ in the sinter decreases and the $\mathrm{MgO} \%$ increases as the $\mathrm{CM}$ percent increases, which is in favor for the blast furnace operation, since the $\mathrm{Mg}$ increases the fluidity of the slag, i.e. decreases the viscosity, which enhances de-sulpherization. $\mathrm{CaO}$ is decreasing as the $\mathrm{CM}$ increases because the $\mathrm{CM}$ contains less $\mathrm{CaO}$ than LS, as was shown in Figure 1.
Table 4 and Figure 3 show the savings in the coke consumption in the sintering process as the result of replacing $\mathrm{LS}$ by $\mathrm{CM}$. The drum test is a standard test in the Iron \& Steel industry used to measure the sizes in the sample. It can be concluded from Table 4 that the total saving of coke in the sintering plant of Hadisolb may reach a value of about $15 \%$, in addition to the saved amount of $L S$ replaced by the $C M$.

\section{Conclusions}

Chemical analysis for the representative sample of $\mathrm{CM}$ showed that it contains a significant amount of organic matter which varies between 10-15\% and this organic matter behaves as a fuel. Pilot scale experiments proved the feasibility of using $\mathrm{CM}$ in the sintering process in the Egyptian Iron and Steel Company (Hadisolb), and this leads to a reduction in coke consumption up to $15 \%$.

Using CM in the calcination furnace at APCC, although found to be technically possible, but not economic.

The use of the CM as a B.F material for the underground cables led to an increase in the current carrying capacity of the underground cables due to its lower thermal resistivity compared to sand. 


\section{Reults of Sintering using Calcareous Mud}

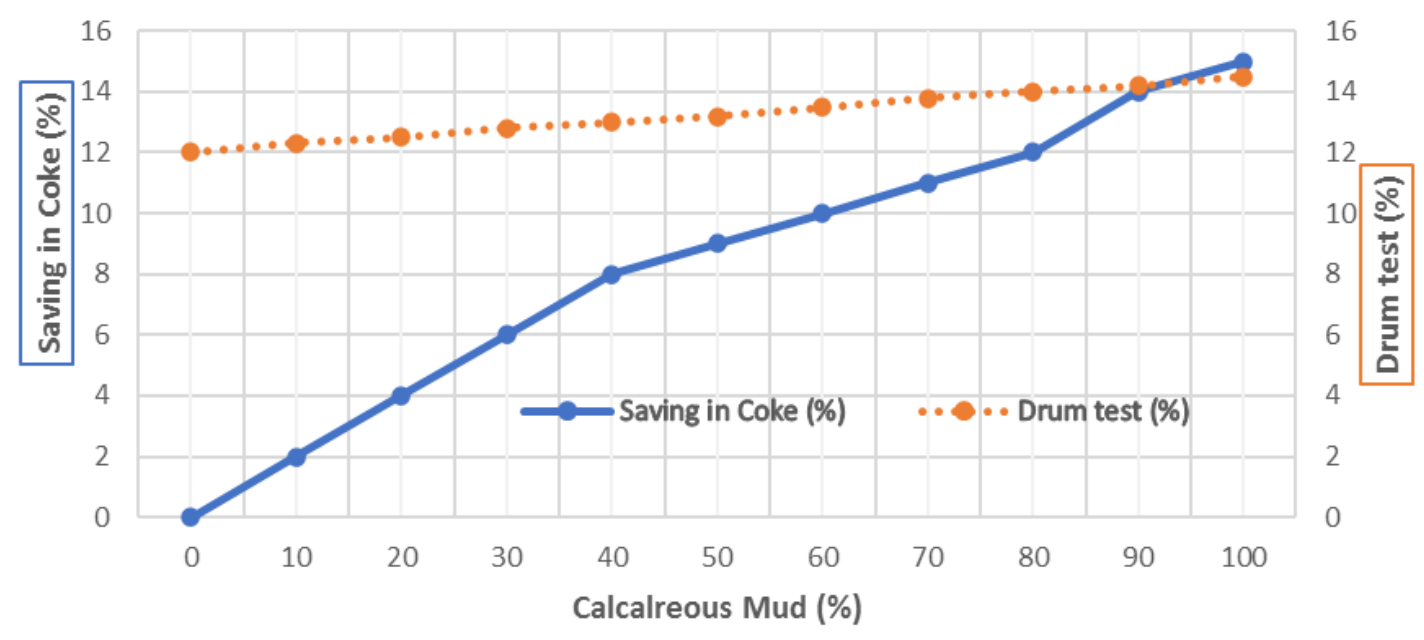

Figure 3: Savings in the coke consumption in the sintering process as the result of replacing LS by CM.s.

\section{References}

1. Elsayed MA Rassoul (2014) The use of calcareous mud in the sintering plant of Hadisolb. Patent No. 28392.

2. Pokhfesnef AN, Rassoul SA, Vegman EF (1962) Isv Vish Uch Chornia Metalurgia 7: 30.

3. Elsayed MA Rassoul, Wilder D (1985) Towards better utilization of raw materials and energy in the metallurgical industry in Egypt, Annual Report, FRCU.

4. RA Abderrassoul, El-Sayed MA Rassoul (1996) Egypt's natural resources management. Fifth International Symposium of the Engineering Management Society, Egypt.

5. Elsayed MA Rassoul (2007-2008) A research project on the reuse of the calcareous mud of the sugar beet companies in the sintering plant of the iron and steel company at El-Tebbin, Egypt.

6. Elsayed MA Rassoul (2017) A new charge mix using the calcareous mud from the sugar beet companies in the sintering of the iron ores. Academy of Scientific Research and Technology, Cairo, Egypt.

7. Elsayed MA Rassoul (2014) A method for increasing the current carrying capacity of the underground cables. Patent No. 28222.

8. A Zaky, I Megahed (1972) Electrical power engineering. ( $1^{\text {st }}$ edn), Al Maarif Establishment-Alexandria, Egypt.

9. Gwefel (1987) Soil science fundamentals. Shenhaby for publishing center, Egypt.

10.R Mahmoud (1985) Determination of code of practice for warming of soil below freezing rooms suitable for Egyptian soil at different localities. Tech Rep, Supreme council of universities, Egypt.

11.Arab Cables Co., Sewedy S.A.E, Egypt.

12.(2008-2009) Egyptian electric utility and consumer protection regulatory agency, Annual Report. 